\title{
A review of national guidelines for management of COPD in Europe
}

\author{
Marc Miravitlles ${ }^{1}$, Claus Vogelmeier ${ }^{2}$, Nicolas Roche ${ }^{3}$, David Halpin ${ }^{4}$, \\ João Cardoso ${ }^{5}$, Alexander G. Chuchalin' ${ }^{6}$, Hannu Kankaanranta ${ }^{7}$, , \\ Thomas Sandström ${ }^{9}$, Paweł Śliwiński ${ }^{10}$, Jaromir Zatloukal ${ }^{11}$ and \\ Francesco Blasi ${ }^{12}$
}

Affiliations: 'Pneumology Dept, University Hospital Vall d'Hebron, Ciber de Enfermedades Respiratorias (CIBERES), Barcelona, Spain. ${ }^{2}$ Dept of Medicine, Pulmonary and Critical Care Medicine, University Medical Center Giessen and Marburg, Philipps-University Marburg, German Center for Lung Research (DZL), Marburg, Germany. ${ }^{3}$ Service de Pneumologie et Soins Intensifs Respiratoires, Hôpital Cochin, University Paris Descartes (EA2511), Paris, France. ${ }^{4}$ Royal Devon and Exeter Hospital, Exeter, UK. ${ }^{5}$ Hospital de Santa Marta, Centro Hospitalar de Lisboa Central, Universidade Nova de Lisboa, Lisbon, Portugal. 'Institute of Pulmonology, Federal Medical and Biological Agency, Moscow, Russia. ${ }^{7}$ Dept of Respiratory Medicine, Seinäjoki Central Hospital, Seinäjoki, Finland. ${ }^{8}$ Dept of Respiratory Medicine, University of Tampere, Tampere, Finland. ${ }^{9}$ Department of Public Health and Clinical Medicine, Medicine Unit, Umeå University, Umeå, Sweden. ${ }^{10}$ 2nd Department of Respiratory Medicine, Institute of Tuberculosis and Lung Diseases, Warsaw, Poland. ${ }^{11}$ Dept of Respiratory Medicine, University Hospital Olomouc, Olomouc, Czech Republic. ${ }^{12}$ Dept of Pathophysiology and Transplantation, Università degli Studi di Milano, IRCCS Fondazione Ospedale Maggiore Policlinico Cà Granda, Milan, Italy.

Correspondence: Marc Miravitlles, Servei de Pneumologia, Hospital Universitari Vall d'Hebron, P Vall d'Hebron 119-129, 08035 Barcelona, Spain. E-mail: mmiravitllesQuvhebron.net

ABSTRACT The quality of care can be improved by the development and implementation of evidencebased treatment guidelines. Different national guidelines for chronic obstructive pulmonary disease (COPD) exist in Europe and relevant differences may exist among them.

This was an evaluation of COPD treatment guidelines published in Europe and Russia in the past 7 years. Each guideline was reviewed in detail and information about the most important aspects of patient diagnosis, risk stratification and pharmacotherapy was extracted following a standardised process. Guidelines were available from the Czech Republic, England and Wales, Finland, France, Germany, Italy, Poland, Portugal, Russia, Spain and Sweden. The treatment goals, criteria for COPD diagnosis, consideration of comorbidities in treatment selection and support for use of long-acting bronchodilators, were similar across treatment guidelines. There were differences in measures used for stratification of disease severity, consideration of patient phenotypes, criteria for the use of inhaled corticosteroids and recommendations for other medications (e.g. theophylline and mucolytics) in addition to bronchodilators.

There is generally good agreement on treatment goals, criteria for diagnosis of COPD and use of longacting bronchodilators as the cornerstone of treatment among guidelines for COPD management in Europe and Russia. However, there are differences in the definitions of patient subgroups and other recommended treatments.

@ERSpublications

There are important differences between European national COPD guidelines http://ow.ly/U2P4y

This article has supplementary material available from erj.ersjournals.com

Received: July 202015 | Accepted after revision: Oct 242015 | First published online: Jan 212016

Support statement: Initial discussions for this publication took place at an advisory board meeting supported by Novartis Pharma AG (Basel, Switzerland). Funding information for this article has been deposited with FundRef.

Conflict of interest: Disclosures can be found alongside the online version of this article at erj.ersjournals.com

Copyright $\odot$ ERS 2016. ERJ Open articles are open access and distributed under the terms of the Creative Commons Attribution Non-Commercial Licence 4.0. 


\section{Introduction}

Chronic obstructive pulmonary disease (COPD) is a critically important international health problem. The prevalence of COPD in Europe has been estimated to range between 4\% and 10\% [1,2], and between 1994 and 2010, 2348184 deaths were attributed to COPD in the European Union [3]. It has been repeatedly suggested that management of the very large number of patients with COPD can be improved by the development and implementation of evidence-based treatment guidelines $[4,5]$.

There are many definitions of clinical guidelines, which may be characterised as: “...systematically developed statements designed to help practitioners and patients decide on appropriate healthcare for specific clinical conditions and/or circumstances" [6]. It has been noted that the difference between a guideline and a statement is based on methodological requirements. For example, an official scientific statement from the European Respiratory Society (ERS) requires a comprehensive scientific review of the literature by an ERS task force, while a clinical practice guideline also includes systematic reviews, grading of the quality of the evidence and grading of recommendation strength $[7,8]$.

In Europe multiple national guidelines for the treatment of COPD exist. It appears important to understand similarities and differences among them and how they might influence patient management in order to improve future guidelines development at both global and national levels. The aim of this review is to carry out a detailed comparison of these guidelines, but not to review them critically.

\section{Methods}

National guidelines for treatment of COPD published in the past 7 years in the European Union and Russia were identified and retrieved. This included guidelines from the Czech Republic [9], England and Wales [10], Finland [11, 12], France [13], Germany [14], Italy [15], Poland [16], Portugal [17], Russia [18], Spain $[19,20]$ and Sweden [21]. Each guideline was reviewed in detail and information about the most important aspects of patient diagnosis, risk stratification and pharmacotherapy was extracted following a standardised process. These included the following: criteria for establishment of a diagnosis of COPD; evaluations used for determination of disease severity and future risk (primarily for exacerbations); definition of patient subgroups employed to guide decisions with respect to initial treatment; treatment goals for patients with stable COPD; choices for initial disease management in different patient subgroups; the role of combination therapy with long-acting $\beta_{2}$-agonists (LABAs) and long-acting muscarinic antagonists (LAMAs), including fixed combinations of these agents; criteria for the use of inhaled corticosteroids (ICS); additional treatments that might be employed for treatment of patients with stable COPD; and the influence of comorbidities on COPD treatment decisions. Extracted information was tabulated for comparison.

\section{Results}

\section{Diagnostic criteria}

The criterion defining airflow obstruction used for the diagnosis of COPD in most national guidelines was a post-bronchodilator forced expiratory volume in $1 \mathrm{~s}(\mathrm{FEV} 1)$ to forced vital capacity (FVC) ratio $<70 \%$ (England and Wales, France, Germany, Finland, Portugal and Russia). The guidelines from the Czech Republic, Italy, Poland and Sweden all specified a post-bronchodilator FEV1/FVC ratio less than the lower limit of normal (LLN) (i.e. below the 5th percentile for age, sex and height). The Spanish guidelines use the fixed ratio as the criterion for diagnosis, except in patients aged $<50$ years and $>70$ years, for whom the LLN is recommended.

\section{Stratification of disease severity and prediction of future risk}

Guidelines from the Czech Republic, England and Wales, France, Germany, Poland, Portugal, Russia and Sweden stratified patients on the basis of the degree of airflow limitation into the four stages set forth in the Global Initiative for Chronic Obstructive Lung Disease (GOLD) strategy, as follows. Stage 1 (mild): FEV1 $\geqslant 80 \%$ predicted; stage 2 (moderate): FEV1 50-79\% pred; stage 3 (severe): FEV1 30-49\% pred; and stage 4 (very severe): FEV $1<30 \%$ pred [22]. The Italian guidelines combined stage 3 and stage 4 in a single "severe" category. The guidelines from Finland identified patients as low risk (FEV1 $\geqslant 50 \%$ pred) and high risk (FEV1 $<50 \%$ pred) and provided a separate tool for assessing severity of airflow obstruction according to GOLD strategy as well as assessing severity of full clinical presentation. The Spanish guidelines did not consider FEV1 alone to categorise patients' severity, but rather used the BODE (body mass index, airflow obstruction, dyspnoea and exercise capacity) index [23] or BODEx (replaces exercise with exacerbations) [24] for patient stratification. With the BODE index, $0-2$ is considered mild COPD, 3-4 moderate, $5-6$ severe and $\geqslant 7$ very severe (table 1 ).

Most guidelines considered symptom severity. Those from the Czech Republic divided patients into groups with COPD assessment test (CAT) scores $<10$ and $\geqslant 10$ or modified Medical Research Council (mMRC) dyspnoea scores of 0 or $\geqslant 1$; those from Finland divided groups into those with CAT $<10$ and $\geqslant 10$; those from Poland and Portugal considered CAT and mMRC scores; those from Russia and Sweden employed CAT, mMRC and clinical COPD questionnaire (CCQ) scores; those from Spain employed CAT scores as a 
TABLE 1 Stratification of chronic obstructive pulmonary disease (COPD) severity/future risk

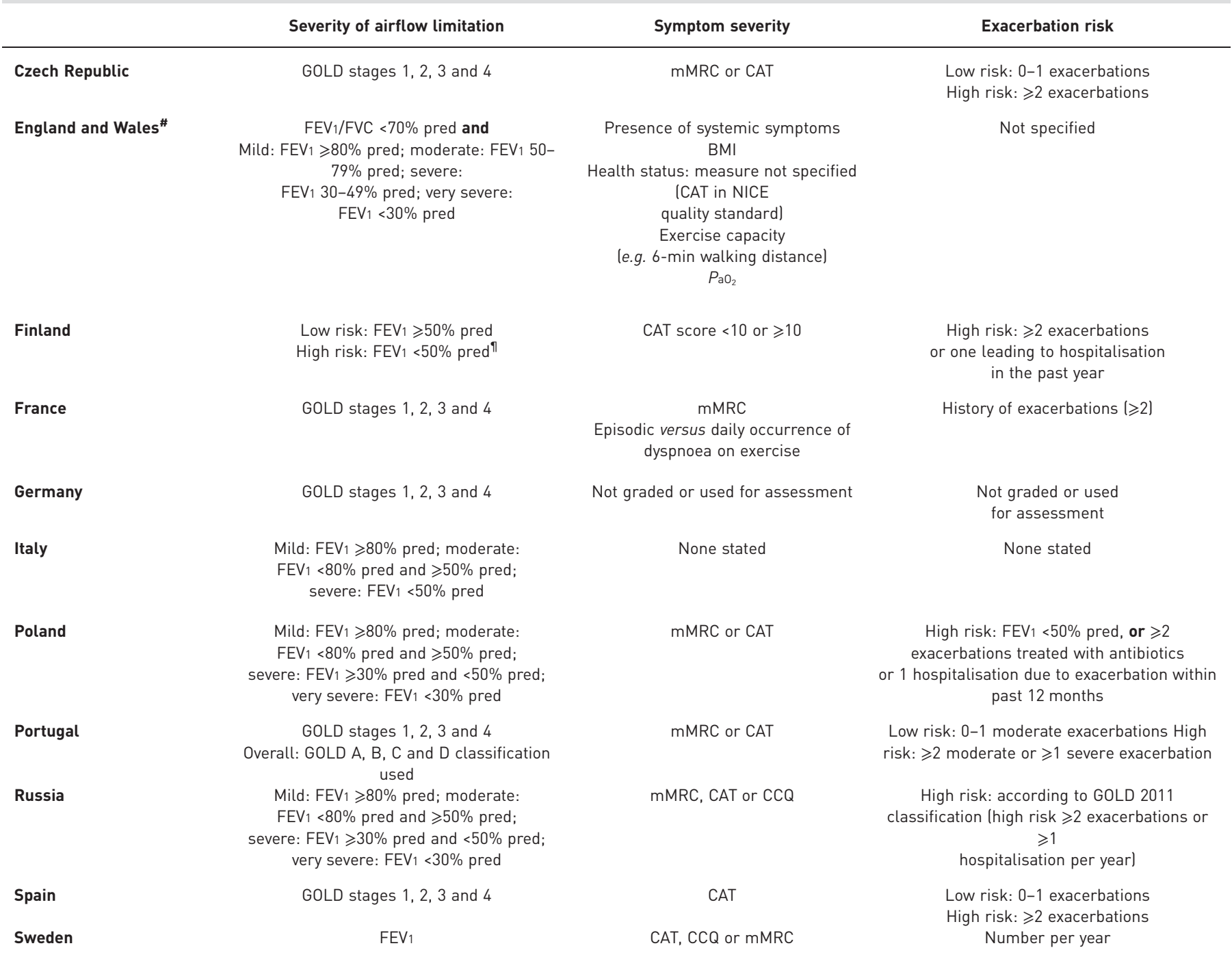

GOLD: Global Initiative for Chronic Obstructive Lung Disease; mMRC: modified Medical Research Council; CAT: COPD assessment test; FEV1: forced expiratory volume in $1 \mathrm{~s}$; FVC: forced vital capacity; BMI: body mass index; NICE: National Institute for Health and Care Excellence; $\mathrm{PaO}_{2}$ : arterial oxygen tension; $\mathrm{CCQ}$ : clinical COPD questionnaire. \#: the guidelines for England and Wales also assess $P \mathrm{aO}_{2} ;{ }^{\text {ๆ: }}$ provides a separate tool for assessing severity of obstruction according to GOLD strategy as well as assessing the severity of full clinical presentation.

measure of disease control at each level of severity [25]; and those from France divided patients on the basis of episodic or daily symptoms and mMRC scores to establish the indications for short- versus long-acting bronchodilators. The guidelines from England and Wales recommend evaluation using the mMRC dyspnoea scale, presence of systemic symptoms, body mass index, health status (measured by CAT), exercise capacity (6-min walking distance) and oxygenation as expressed arterial oxygen tension for a more detailed determination of disease severity if necessary (table 1).

\section{Recognition of patient subtypes or phenotypes}

There was variability across national guidelines with respect to the identification of patient subtypes, and this may be related, at least in part, to the times at which different guidelines were published. For example, the oldest guidelines included in the analysis were from Germany and do not consider phenotypes, while more recent guidelines generally recognise multiple patient phenotypes. The classic phenotypes of chronic bronchitis and emphysema were recognised in recommendations from the Czech Republic, England and Wales, Poland, Russia, Spain and Sweden (bronchitic only) (table 2).

The asthma-COPD overlap syndrome (ACOS) phenotype was recognised in recommendations from the Czech Republic, Finland, Russia, Spain and Sweden. As noted earlier, this phenotype was not specifically 
TABLE 2 Patient phenotypes/groups to guide treatment decisions

$\begin{array}{ccccc}\begin{array}{c}\text { Use of phenotypes/ } \\ \text { groups }\end{array} & \text { Type } 1 & \text { Type } 2 & \text { Type } 3 & \text { Type } 4\end{array}$

\begin{tabular}{|c|c|c|c|c|c|}
\hline Czech Republic ${ }^{\#}$ & Yes & $\begin{array}{c}\text { Bronchitic: productive } \\
\text { cough over } \geqslant 3 \text { months } \\
\text { in } \geqslant 2 \text { consecutive } \\
\text { years }\end{array}$ & $\begin{array}{l}\text { Emphysematous: } \\
\text { absence of productive } \\
\text { cough and signs of } \\
\text { emphysema }\end{array}$ & $\begin{array}{c}\text { Frequent exacerbator: } \\
\geqslant 2 \text { per year treated } \\
\text { with antibiotics or } \\
\text { corticosteroids }\end{array}$ & $\begin{array}{l}\text { COPD-asthma } \\
\text { overlap (ACOS) }\end{array}$ \\
\hline England and Wales & Yes & $\begin{array}{c}\text { Chronic productive } \\
\text { cough }\end{array}$ & $\begin{array}{l}\text { Breathlessness and } \\
\text { exercise limitation }\end{array}$ & Frequent exacerbator & $\begin{array}{l}\text { Smoking, respiratory } \\
\text { failure, cor } \\
\text { pulmonale, abnormal } \\
\text { BMI and anxiety and } \\
\text { depression }\end{array}$ \\
\hline Finland & Yes & & $\begin{array}{l}\text { Low exacerbation } \\
\text { risk: infrequent } \\
\text { previous } \\
\text { exacerbations, FEV } 1 \\
\geqslant 50 \% \text { pred, no typical } \\
\text { features of ACOS }\end{array}$ & $\begin{array}{l}\text { High exacerbation } \\
\text { risk: history of } \\
\text { exacerbations, FEV } 1 \\
<50 \% \text { pred, no typical } \\
\text { features of ACOS }\end{array}$ & $\begin{array}{l}\text { Overlap: there are } \\
\text { features of both } \\
\text { asthma and COPD }\end{array}$ \\
\hline Germany & No & & & & \\
\hline Italy & Yes & Airflow limitation & Emphysema & & \\
\hline Poland & Yes & $\begin{array}{c}\text { Chronic bronchitis: } \\
\text { dominant symptoms } \\
\text { are cough and sputum } \\
\text { production }\end{array}$ & $\begin{array}{c}\text { Emphysema: } \\
\text { dominant symptoms } \\
\text { are dyspnoea during } \\
\text { exercise, radiographic } \\
\text { characteristics }\end{array}$ & $\begin{array}{l}\text { Frequent exacerbator: } \\
\geqslant 2 \text { exacerbations } \\
\text { treated with antibiotics } \\
\text { and/or oral steroids } \\
\text { within } 12 \text { months }\end{array}$ & \\
\hline Spain & Yes & $\begin{array}{l}\text { Chronic bronchitis: } \\
\text { divided into } \\
\text { exacerbators and } \\
\text { nonexacerbators }\end{array}$ & $\begin{array}{l}\text { Emphysema: divided } \\
\text { into exacerbators and } \\
\text { nonexacerbators }\end{array}$ & $\begin{array}{c}\text { Exacerbator: } \geqslant 2 \\
\text { exacerbations per year } \\
\text { Nonexacerbator: }<2 \\
\text { exacerbations per year }\end{array}$ & ACOS \\
\hline Sweden & Yes & $\begin{array}{l}\text { Bronchitic: based on } \\
\text { lung function } \\
\text { evaluation (may } \\
\text { indicate responsivity } \\
\text { to roflumilast) }\end{array}$ & & $\begin{array}{l}\text { Frequent exacerbator: } \\
\geqslant 2 \text { exacerbations per } \\
\text { year (especially } \\
\text { important if consistent } \\
\text { for } \geqslant 2 \text { years) }\end{array}$ & $\begin{array}{c}\text { ACOS: characteristics } \\
\text { of both COPD and } \\
\text { asthma }\end{array}$ \\
\hline
\end{tabular}

COPD: chronic obstructive pulmonary disease; ACOS: asthma-COPD overlap syndrome; BMI: body mass index; FEV1: forced expiratory volume in $1 \mathrm{~s} .{ }^{\#}$ : recommendations also include COPD + bronchiectasis and pulmonary cachexia phenotypes. 
recognised in recommendations from Germany and this was also the case for France and Italy. In the Czech Republic guidelines, the major criteria for a diagnosis of ACOS in a patient that also meets the criteria for a diagnosis of COPD were the degree of reversibility in bronchodilator testing (FEV1 $>15 \%$ pred and $>400 \mathrm{~mL}$ ), exhaled nitric oxide fraction $\left(F_{\mathrm{eNO}}\right) \geqslant 45-50 \mathrm{ppb}$ and/or elevated sputum eosinophils $\geqslant 3 \%$, and history of asthma. In the Finnish guidelines, major diagnostic criteria for ACOS included a significant bronchodilator response (FEV $1>15 \%$ pred and $>400 \mathrm{~mL}$ ), sputum eosinophilia or elevated $F_{\text {eNO }}(>50 \mathrm{ppb}$ ), and previous symptoms compatible with asthma starting when the patient was $<40$ years of age in addition to meeting the criteria for a diagnosis of COPD. The Spanish guidelines include a positive bronchodilator test (increase in FEV $1>15 \%$ and $>400 \mathrm{~mL}$ ), eosinophilia in sputum and a personal history of asthma as major criteria for ACOS. Criteria for a diagnosis of ACOS are not stated in the Polish and Russian guidelines.

The frequent exacerbator phenotype was recognised in recommendations from the Czech Republic, England and Wales, Finland, Poland, Portugal, Russia, Spain and Sweden. Those from the Czech Republic defined frequent exacerbators as those with a history of two or more exacerbations in the past year. The guidelines from Finland, Russia, Portugal and Spain defined frequent exacerbators as those who had two or more exacerbations or one or more severe exacerbation leading to hospitalisation in the previous year. The guidelines from Poland used these criteria and also included those with $\mathrm{FEV}_{1}<50 \%$ pred as being likely to have exacerbations. Guidelines from Sweden also considered the number of exacerbations in the previous year for patient stratification. French guidelines identified patients with repeated exacerbations, mostly for the purpose of defining some treatment indications (indication for ICS + LABA combination, see later).

\section{Treatment goals}

Recommendations from the majority of countries identified decreasing severity of current symptoms, reducing future risk for exacerbations, slowing disease progression and/or lowering mortality as significant treatment goals. The guidelines from the Czech Republic, Finland, France, Poland, Portugal and Sweden all cited reducing symptoms, averting the natural progression of the disease, improving quality of life, enhancing physical activity, preventing complications and adverse consequences and increasing life expectancy as treatment goals. Those from Germany and Spain included improvement of symptoms, exercise capacity, quality of life and reduction of exacerbation frequency. The guidelines from Russia had short-term goals of symptom relief and improvement of exercise tolerance and quality of life and long-term goals of preventing disease progression and exacerbations and decreasing mortality. While overall treatment goals were not explicitly stated in the Italian guidelines, they did note that the main goal of pharmacotherapy for patients with COPD was bronchodilation.

\section{Treatment selection}

Recommended initial pharmacotherapy was generally a short-acting $\beta_{2}$-agonist (SABA) or short-acting antimuscarinic agent (SAMA) in patients with mild disease. In more symptomatic patients, a LABA or LAMA was the preferred treatment. No guideline provided precise criteria to choose between these options. The association of LABA + LAMA was an alternative choice in the Czech Republic, England and Wales, Finland, Italy, Poland, Russia, Spain and Sweden; in France, it was to be considered when a single agent did not provide satisfactory effectiveness; and it was a major choice for GOLD group C patients in Sweden. Recommendations from Poland, Portugal, Russia and Sweden stratified initial treatment on the basis of the GOLD A-D classification scheme [22]; and both France and Germany based treatment selection mainly on the severity of airflow obstruction according to GOLD spirometric severity stage [22] (table 3). The French guidelines also considered the burden of dyspnoea for choosing between short-acting and long-acting bronchodilators and exacerbations in deciding whether to employ ICS + LABA combinations in patients with severe airflow obstruction.

Several guidelines tailored preferred treatment recommendations on the basis of patient phenotype. Guidelines from the Czech Republic indicated that bronchitic patients might require a phosphodiesterase (PDE) type 4 inhibitor, a mucoactive agent, and/or macrolide added to bronchodilator treatment and that patients with emphysema might also receive theophylline. Recommendations for patients with ACOS included ICS + LABA or ICS + LABA + LAMA (Czech Republic, Finland and Spain) and the possibility of adding a leukotriene response modifier (Czech Republic, but not supported by any clinical trial results in patients with ACOS). Recommendations for preferred therapy for frequent exacerbators included standard treatment and PDE4 inhibitor, ICS + LABA, mucoactive drugs and antibiotics (Czech Republic); ICS + LABA (France); ICS + LABA or LAMA (Finland, Spain and Poland); addition of ICS to a long-acting bronchodilator (Germany); and LAMA, ICS + LABA, LABA + LAMA or ICS + LABA + LAMA (England and Wales).

Recommendations for treatment with LABA + LAMA varied across national guidelines (table 4). Combination of LABA + LAMA was listed as an alternative choice in the guidelines from Finland, France, Poland, Portugal and Spain. In Germany and Russia, LABA + LAMA combination was a first choice for 
TABLE 3 Preferred first treatment choice

\begin{tabular}{|c|c|c|c|c|}
\hline & Patient type 1 & Patient type 2 & Patient type 3 & Patient type 4 \\
\hline England and Wales & $\begin{array}{l}\text { Breathlessness and exercise } \\
\text { limitation: SABA or SAMA }\end{array}$ & $\begin{array}{c}\text { Exacerbations or } \\
\text { breathlessness and FEV } 1 \\
\geqslant 50 \% \text { pred: LABA or LAMA }\end{array}$ & $\begin{array}{c}\text { Exacerbations or } \\
\text { breathlessness and } \\
\text { FEV } 1<50 \% \text { : LAMA or } \\
\text { ICS + LABA }\end{array}$ & $\begin{array}{c}\text { Persistent exacerbations or } \\
\text { breathlessness: ICS + LABA or } \\
\text { LABA + LAMA if ICS declined or } \\
\text { not tolerated or LAMA + ICS + } \\
\text { LABA }\end{array}$ \\
\hline Finland & $\begin{array}{c}\text { Low risk for exacerbations: SABA } \\
\text { or SAMA }\end{array}$ & $\begin{array}{l}\text { Low risk for exacerbations: } \\
\text { LABA or LAMA }\end{array}$ & $\begin{array}{l}\text { High risk for exacerbations: } \\
\text { LAMA or ICS + LABA }\end{array}$ & $\begin{array}{c}\text { ACOS: at least ICS + LABA or } \\
\text { ICS + LABA + LAMA }\end{array}$ \\
\hline France & GOLD 1: SABA or SAMA (or both) & $\begin{array}{c}\text { GOLD 2: LABA or LAMA (both } \\
\text { if dyspnoea persists during } \\
\text { usual exercise) }\end{array}$ & $\begin{array}{l}\text { GOLD 3: ICS + LABA if } \\
\text { repeated exacerbations or } \\
\text { LABA + LAMA }\end{array}$ & $\begin{array}{c}\text { GOLD 4: triple therapy } \\
\text { (ICS + LABA + LAMA) if } \\
\text { previous step is not sufficient }\end{array}$ \\
\hline Italy & $\begin{array}{l}\text { Symptomatic with confirmed } \\
\text { diagnosis of COPD, mMRC stage } \\
\geqslant 1 \text { and prebronchodilator } \mathrm{FEV} 1 \\
\geqslant 80 \% \text { pred: consider treatment } \\
\text { with bronchodilators }\end{array}$ & $\begin{array}{l}\text { Symptomatic with confirmed } \\
\text { diagnosis of COPD and } \\
\text { prebronchodilator FEV } 1<80 \% \\
\text { pred: consider LABA }\end{array}$ & $\begin{array}{l}\text { If patient / physician not } \\
\text { satisfied: increase } \\
\text { bronchodilator dose; add } \\
\text { second category LABD; add } \\
\text { ICS in frequent exacerbators }\end{array}$ & \\
\hline Poland & $\begin{array}{c}\text { CAT }<10, F E V_{1} \geqslant 50 \% \text { pred, low } \\
\text { exacerbation: SABA or SAMA }\end{array}$ & $\begin{array}{c}\text { CAT } \geqslant 10, \text { FEV }_{1} \geqslant 50 \% \text { pred, } \\
\text { low exacerbation: LABA or } \\
\text { LAMA }\end{array}$ & $\begin{array}{c}\text { CAT }<10, \text { FEV }_{1}<50 \% \text { pred, } \\
\text { high exacerbation: LAMA or } \\
\text { ICS + LABA }\end{array}$ & $\begin{array}{c}\text { CAT } \geqslant 10, \text { FEV }_{1}<50 \% \text { pred, high } \\
\text { exacerbation: LAMA and/or ICS } \\
+ \text { LABA }\end{array}$ \\
\hline Portugal & GOLD A: SABA or SAMA & GOLD B: LABA or LAMA & $\begin{array}{l}\text { GOLD C: LAMA or } \\
\text { ICS + LABA }\end{array}$ & $\begin{array}{l}\text { GOLD D: LAMA and/or } \\
\text { ICS + LABA }\end{array}$ \\
\hline Russia & GOLD A: SABA or SAMA & GOLD B: LABA or LAMA & $\begin{array}{l}\text { GOLD C: LAMA or } \\
\text { ICS + LABA }\end{array}$ & $\begin{array}{c}\text { GOLD D: ICS + LABA } \\
\text { LAMA, ICS + LABA } \\
\text { + LAMA }\end{array}$ \\
\hline
\end{tabular}

PDE: phosphodiesterase; BVR: bronchoscopic volume reduction; LVRS: lung volume reduction surgery; $\alpha_{1}$-AT: $\alpha_{1}$-antitrypsin; ICS: inhaled corticosteroid; LABA: long-acting $\beta_{2}$-agonist; ACOS: asthma-chronic obstructive pulmonary disease (COPD) overlap syndrome; LAMA: long-acting muscarinic antagonist; SABA: short-acting $\beta_{2}$-agonist; SAMA: short-acting muscarinic antagonist; FEV 1 : forced expiratory volume in 1 s; GOLD: Global Initiative for Chronic Obstructive Lung Disease; LTOT: long-term oxygen therapy; mMRC: modified Medical Research Council; LABD: long-acting bronchodilator; CAT: COPD assessment test. \#: recommendations for standard treatments include inhaled bronchodilators (LABA, LAMA, ultra-LABA and ultra-LAMA), pulmonary rehabilitation, vaccination, education, long-acting muscarinic antagonist, inhalation training, dietary changes, comorbidity treatment and risk elimination. Patients with COPD and bronchiectasis receive a PDE4 inhibitor, mucoactive drugs, antibiotics and physiotherapy; and those with pulmonary cachexia receive rehabilitation and nutritional support.

treatment of specific patient subgroups, whereas in the Czech Republic combination therapy was an option for all patients. In England and Wales, a LABA + LAMA combination was recommended in patients where LABA + ICS were indicated, but ICS was declined or could not be tolerated. It may also be considered in patients with persistent breathlessness despite treatment with LAMA, LABA or LABA + ICS. None of the guidelines provided specific recommendations regarding the use of fixed-dose LABA + LAMA combinations.

In the majority of guidelines, the criteria for the proper use of ICS were roughly similar. ICS was recommended in combination with bronchodilators in patients with $\mathrm{FEV}_{1}<50 \%$ (or $<60 \%$ ) pred, at high risk for exacerbations and/or with a history of two or more exacerbations in the previous year, as well as in those with ACOS. In patients without ACOS, ICS use was generally restricted to patients not effectively managed with bronchodilators alone, and usually to those with two or more exacerbations per year, eventually further restricted to patients with severe airflow obstruction (France) (table 4). 
TABLE 4 Use of long-acting $\beta_{2}$-agonist (LABA) + long-acting muscarinic antagonist (LAMA) combinations and inhaled corticosteroids (ICS)

LABA + LAMA

Option for all patients; depends on severity

Consider in patients indicated for ICS + LABA if ICS refused or cannot be tolerated Consider in patients with persistent breathlessness despite treatment with LAMA, LABA or ICS + LABA

Czech Republic England and Wales

Finland

France

Germany

Italy

Poland

Portugal

Russia

Spain

Sweden
GOLD stage 2 patients if there is dyspnoea during usual activities despite single long-acting bronchodilator GOLD stages 3 and 4

GOLD stage 2 and higher (possibly triple therapy and additional treatments in GOLD stages 3 and 4]

A second long-acting bronchodilator with a complementary mechanism of action may be added if the patient and/or physician are not satisfied with the response to single-agent therapy

Alternative choice

Alternative choice

First choice in GOLD D patients Alternative choice in GOLD B and C patients

Alternative choice (nonexacerbator)

Alternative choice in GOLD B patients First choice in GOLD C and D patients

ICS

Patient with ACOS or frequent exacerbator

Patients who remain breathless or have exacerbations despite using short-acting bronchodilators and $\mathrm{FEV}_{1}<50 \%$ pred and in patients with $\mathrm{FEV}_{1} \geqslant 50 \%$ pred who remain breathless or have exacerbations despite maintenance therapy with a LABA; increased risk of pneumonia is mentioned

Patient belongs to high exacerbation risk group (frequent exacerbations despite the use of appropriate bronchodilator therapy, FEV1 $<50-70 \%$ pred) or presents with ACOS; increased risk of pneumonia is mentioned

Used only as part of fixed-dose combinations; FEV $1<50 \%$ pred ( $<60 \%$ pred for salmeterol/fluticasone) and repeated exacerbations

$l \geqslant 2$ per yearl and symptoms despite regular treatment with bronchodilator(s) (LABA and/or LAMA)

FEV $1<50 \%$ pred and $\geqslant 1$ exacerbation treated with systemic steroids and/or antibiotics in the past year

In symptomatic patients, with prebronchodilator $\mathrm{FEV}_{1}<60 \%$ pred and $\geqslant 2$ exacerbations per year; ICS may be added to LABA

$\geqslant 2$ COPD exacerbations treated with antibiotics/oral steroids or $\geqslant 1$ hospitalisation due to COPD exacerbation within past 12 months, or FEV $1<50 \%$ pred

ICS are recommended in GOLD classes $C$ and D; no specific criteria are stated for use in these classes, but frequent exacerbations should prompt augmentation of therapy

Frequent exacerbations, sputum eosinophilia or systemic inflammation; increased risk of pneumonia is mentioned

ACOS, exacerbator phenotype despite optimal bronchodilation; increased risk of pneumonia is mentioned

Repeated exacerbations or FEV $1<50-60 \%$ pred

ACOS: asthma-chronic obstructive pulmonary disease (COPD) overlap syndrome; FEV1: forced expiratory volume in $1 \mathrm{~s}$; GOLD: Global Initiative for Chronic Obstructive Lung Disease.

Additional treatments were considered in all recommendations (table 5). Theophylline was recommended with reservations by all countries except Italy. Roflumilast was recommended in patients with severe COPD with characteristics of chronic bronchitis and a history of exacerbations in most countries. However, this agent is not available or not reimbursed in England and Wales, France, Poland and Portugal. It is currently reimbursed in Germany, but was not available at the time the guidelines were written. Macrolides could be used as alternative treatment for stable disease in patients still experiencing exacerbations despite optimal treatment in the Czech Republic, Finland, Russia and Spain. They were not recommended for stable disease in Poland, and other countries did not provide recommendations. $\mathrm{N}$-acetylcysteine/oral carbocisteine were both recommended in the Czech Republic, England and Wales (with caveats), Poland, Russia and Spain, but not recommended in Finland, France and Portugal.

\section{Impact of comorbidities on COPD treatment decisions}

Recommendations from most countries (England and Wales, France, Germany, Italy, Poland, Portugal, Spain and Sweden) did not suggest alterations in COPD treatment in patients with common comorbidities (online supplementary table S1). However, they did indicate that comorbidities should be evaluated and appropriately managed. Recommendations from Finland and Russia suggested caution/careful consideration regarding use of ICS in patients with or at risk of osteoporosis, diabetes and pneumonia; and also for high-dose $\beta_{2}$-agonists in patients with cardiovascular disease. 
TABLE 5 Additional treatments for stable chronic obstructive pulmonary disease (COPD)

\begin{tabular}{|c|c|c|c|c|c|}
\hline & Theophylline & Roflumilast & Macrolide & $\mathrm{N}$-acetylcysteine & Oral carbocisteine \\
\hline England and Wales & $\begin{array}{l}\text { REC: after inhaled } \\
\text { treatments }\end{array}$ & NR & NR & REC & NR \\
\hline France & $\begin{array}{l}\text { REC: only when } \\
\text { treatment goals are not } \\
\text { attained with inhaled } \\
\text { treatments }\end{array}$ & Not reimbursed & NR & NO & NO \\
\hline Italy & NR & $\begin{array}{l}\text { REC: for patients not controlled } \\
\text { with bronchodilators, FEV } 1 \\
<50 \% \text { pred, } \geqslant 2 \text { exacerbations } \\
\text { per year and chronic bronchitis }\end{array}$ & NR & NR & NR \\
\hline Poland & REC: with qualifications & REC: not reimbursed & NO & REC & REC \\
\hline Portugal & $\begin{array}{l}\text { REC: only if better } \\
\text { options cannot be used }\end{array}$ & Not available & NR & NR & NR \\
\hline
\end{tabular}

REC: recommended; NR: no recommendation; FEV1: forced expiratory volume in $1 \mathrm{~s}$; NO: not recommended.

\section{Discussion}

The European and Russian guidelines for the treatment of COPD have numerous differences when considered in detail, but they also have many general similarities with respect to both diagnosis and management of patients with this disease. There are many potential reasons for differences between guidelines, which might include differences in national healthcare systems, differences in opinions regarding cost-effectiveness of drugs, reimbursement issues and availability of medications. However, it is reasonable to suggest that one of the most important reason for differences among guidelines is the evidence available at the times when they were developed. The publication dates for the guidelines reviewed ranged from 2007 for Germany to 2015 for Finland.

The guidelines generally encourage the consideration of a diagnosis of COPD and evaluation with spirometry in symptomatic patients with risk factors, most notably tobacco smoking [9, 10, 12, 15]. However, review of these recommendations prompts the suggestion that simplification of diagnostic criteria, particularly for primary care physicians, could significantly enhance patient identification and initiation of care. This is an important issue since multiple studies from Europe have indicated that COPD is greatly underdiagnosed [1,26-31].

There was one notable difference among countries with respect to diagnosis of COPD. The guidelines from England and Wales, Finland, France, Germany, Portugal and Russia all used FEV1/FVC $<70 \%$ as the spirometric criterion for a diagnosis of persistent airway obstruction and COPD, while the Czech Republic, Italy, Poland and Sweden used FEV1/FVC $<$ LLN. It has been considered that the use of the fixed ratio 
FEV1/FVC $<70 \%$ yields false negative results in individuals aged $<50$ years and false positive results in those aged $>70$ years [32-34]. However, a fixed ratio appears to be much simpler to implement, especially in non-specialised settings. For this reason, the Spanish guidelines suggest using the LLN criterion for individuals in those age groups $[19,35]$.

All guidelines used the same cut-offs for FEV1 in defining the severity of airflow obstruction. Most of the guidelines reviewed (exceptions were Germany and Italy) used a combination of measures for the determination of disease severity, impact and establishment of patient prognosis. This is consistent with results of numerous studies indicating that FEV1 alone does not provide the best prediction of treatment outcomes for patients with COPD [23, 36-38]. Consideration of guidelines and the clinical literature supports the view that assessment of disease severity and establishment of prognosis should be based on multiple factors, including exacerbation history, symptoms (including activity limitation) and pulmonary function $[23,24,39]$. This is reflected in the Spanish guidelines which employ BODE [23] or BODEx [24] for patient stratification. The utility of these two metrics for patient stratification and outcome prediction is supported by results from multiple studies. The BODE index is also mentioned for severity assessment in the French guidelines. It has been shown to be a significant predictor of exacerbations, hospitalisation, quality of life and respiratory and all-cause mortality in patients with COPD [23, 40-43]. The Spanish guidelines recommend the use of the BODEx, which replaces exercise capacity with exacerbation history, as an alternative to the BODE index in patients with GOLD stage I or II disease [19, 35]. This simplifies patient evaluation with no decrement in predictive value for mortality [24]. The extensive use of these composite measures and validation of their predictive value for multiple end-points supports their routine use in the initial assessment of patients with COPD.

The guidelines reviewed were in agreement regarding the existence of distinct subgroups of COPD patients, and the ACOS and frequent exacerbator "phenotypes" were generally accepted $[9,10,12,16-19$, 21, 35]. Results from the Evaluation of COPD Longitudinally to Identify Predictive Surrogate Endpoints (ECLIPSE) study and other evaluations have suggested that the frequent exacerbator phenotype is relatively stable over a 3-year follow-up [44]. However, consideration of guidelines also indicates that it is not clear whether some COPD phenotypes are stable or can change with therapy and thus might be best considered as treatable characteristics rather than definitive traits in specific patients.

For most guidelines, patients with ACOS have disease characterised by increased reversibility of airflow obstruction, eosinophilic bronchial and systemic inflammation and increased responsivity to ICS, compared with other COPD patients. They also have more frequent exacerbations and more wheezing and dyspnoea [45-48]. While clear criteria for the diagnosis of ACOS have been set forth $[9,12,19,35]$, they have not been prospectively validated. In addition, a question that remains unanswered is whether ACOS should be considered as a distinct entity or rather as concomitant diseases that overlap [49].

There also has been considerable discussion regarding whether subgroups of patients with different clinical characteristics should be considered as distinct phenotypes and whether or not this term is useful for patient description, especially as drivers for treatment decisions $[20,35,50]$. Consideration of patient subgroups with COPD is further complicated by the fact that many have multiple comorbid conditions, including cardiovascular disease [51], lung cancer [52], frequent respiratory tract infections [53], osteoporosis [54], diabetes [55], metabolic syndrome [56] and psychiatric disease [57]. The guideline for England and Wales is innovative in advocating a simultaneous multidimensional assessment and management approach that includes comorbidities/systemic effects of COPD. There is general recognition that comorbidities should be integrated into guidelines developed for the management of patients with COPD [58].

There was general good agreement between guidelines with respect to the selection of preferred therapy in patients with different disease severities. However, the selection of "initial" therapy by a pulmonologist is complicated by the fact that most COPD patients are initially managed by general practitioners prior to referral and there is little evidence-based guidance for treatment selection in post-referral patients who have already been treated. Most patients with COPD are symptomatic by the time they are referred to a pulmonologist and should therefore receive treatment with long-acting bronchodilators. At present, we do not have evidence that provides a basis for stepping up or down treatment in patients with COPD and research addressing these questions is greatly needed.

More information is also needed regarding the benefits of a LABA + LAMA combination versus either agent alone. Results from several studies have made clear that combination of LABA + LAMA provides improvements in pulmonary function significantly greater than those achieved with monotherapy [59-61]. There is a growing body of evidence supporting the benefits of LABA + LAMA therapy versus single agents for reducing symptoms and decreasing the frequency of exacerbations [59-63], but more information is awaited about the comparison of LABA + LAMA versus LABA + ICS for the prevention of exacerbations in high-risk patients.

Inhaled corticosteroids are effective in patients with ACOS [64, 65], and they have a significant benefit in decreasing exacerbations and reducing symptom severity in other groups of COPD patients [66, 67]. 
However, there are some risks of significant side-effects (e.g. pneumonia) associated with ICS use [68-70], which must be considered in any treatment recommendations regarding these agents. Selection of candidates for ICS treatment would be facilitated by the availability of biomarkers predicting effectiveness (e.g. elevated sputum $[64,71]$ or blood eosinophils [72]), but more research is needed in this "hot topic" area.

Guidelines for diagnosis, assessment and management of patients with COPD generally lack a formal definition of disease control that takes into account COPD severity at the initiation of treatment and which can be used to evaluate efficacy of therapy. It is reasonable to suggest that such a definition should be included in treatment recommendations. SOLER-CATALUÑa et al. [25] have set forth criteria for control of disease that consider both impact of disease, as measured by instruments such as the CAT or CCQ, and stability, as reflected by an absence of exacerbations and no deterioration in questionnaire results. Using this approach, treatment is intensified or decreased, as appropriate to maintain stability and low impact [25]. Addition of criteria for longitudinal patient assessment and adjustment of therapy may be a useful addition to treatment guidelines.

Guidelines for the treatment of any disease have little meaning unless they are integrated into clinical practice [73]. Results from multiple surveys indicate that actual treatment for many patients with COPD may not be consistent with available treatment recommendations. A recent analysis of prescribing patterns in 24957 patients revealed that COPD was not treated according to GOLD and National Institute for Health and Care Excellence recommendations in the UK primary-care setting, with significant proportions of patients receiving no treatment despite experiencing symptoms [26]. Interestingly, most COPD patients received ICS irrespective of severity of airflow limitation, asthma diagnosis and exacerbation history, whereas many patients on treatment were still symptomatic [26]. An observational study which included information from 4094 patients with COPD treated in Italy also indicated poor adherence to GOLD treatment recommendations, with $62.1 \%$ of the patients receiving pharmacotherapy that was inappropriate for their disease severity [74]. An evaluation of 1355 patients with COPD in the Czech Republic indicated that $32.8 \%$ of cases were misclassified according to GOLD categories. Furthermore, $15.4 \%$ of patients received ICS unnecessarily, whereas in $15.8 \%$ of cases ICS were erroneously omitted [75]. In a French cohort study, ICS were prescribed outside their indications in $\sim 75 \%$ of patients if the "old" GOLD guidelines were taken as the reference, and in one-third when considering the new GOLD document $[76,77]$. This study also underlined the high proportion of patients on triple therapy, which is supported by only a few studies and contradicted by others [78-80].

Physicians' reports of their own practice patterns also indicate variability regarding adherence to and knowledge of treatment guidelines. A survey of 1307 primary-care physicians and respiratory specialists who regularly managed patients with COPD, emphysema or chronic bronchitis indicated good awareness of guidelines and frequent use of recommended diagnostic practices. However, there were significant deviations from guideline-recommended treatment. Physicians reported using spirometry routinely (primary-care physicians $82 \%$ and respiratory specialists 100\%) to diagnose COPD and frequently included validated patient-reported outcome measures (primary-care physicians 67\% and respiratory specialists $81 \%$ ). The percentages of primary-care physicians and respiratory specialists providing first- or second-choice treatment consistent with the GOLD recommendations for a type B patient were $38 \%$ and $67 \%$, respectively. Those for type C patients were $40 \%$ and $38 \%$, respectively and those for type D patients were $57 \%$ and $58 \%$, respectively [81]. In contrast, a survey of 590 respiratory specialists in Germany indicated good knowledge of approaches to COPD diagnosis and classification as well as treatment selection for patients with moderate or severe disease [82].

The limited adherence to COPD treatment guidelines may reflect issues that are not fully addressed due to insufficient information available from controlled clinical trials [8] and possibly also by the view that they reflect greater clinical efficacy in controlled trials than treatment effectiveness achievable in broad patient populations being managed in routine care in real-world settings [83].

Providing concise and succinct treatment recommendations relevant for both general and specialist physicians may improve their employment for guidance of patient management. The ERS has noted the importance of trustworthy documents to guide patient management and have established a guidelines working group to facilitate development, dissemination and implementation of guidelines [7]. However, it is also recognised that the methodology involved in the development of such guidelines requires specialised knowledge (e.g. application of the GRADE (Grading of Recommendations, Assessment, Development and Evaluation) criteria to information providing the basis for the guidelines) and is time consuming and very costly [84]. A potentially efficient approach for the development of COPD treatment guidelines may be initial formulation at the international level and adaptation based on the needs and resources in each country. This suggestion is consistent with the ERS proposal that scientific societies should work together and establish panels to provide appropriate guidance regarding respiratory disease to physicians and patients [7]. 
In conclusion, the review of guidelines indicated several areas that should be addressed and questions that need to be answered to facilitate diagnosis and treatment of COPD (online supplementary table S2): 1) recommendations should increase suspicion of COPD among primary care physicians, who are usually the first to encounter these patients; 2) there are distinct constellations of patient characteristics that may be useful for establishment of prognosis and guiding treatment selection, but it is not clear whether they should be considered as permanent phenotypes or treatable characteristics; 3) better guidance is needed for patient treatment (stepping up or down treatment); 4) SABAs and SAMAs are suboptimal as regular treatment for symptomatic individuals with COPD, since long-acting bronchodilators are superior; 5) more information is needed about the long-term efficacy and safety of LABA + LAMA combinations versus single agents and it is most important to understand their efficacy on symptoms and exacerbations; and 6) both the potential risks and benefits should guide selection of treatments (this seems particularly important for ICS).

It is important that guidelines be updated regularly to keep pace with that of research on the diagnosis, characterisation and management of patients with COPD. This is becoming increasingly difficult due to the vast effort, time and expense associated with guideline development [85] and the growing abundance of clinically relevant literature. Maintaining good alignment of treatment recommendations and clinical research results might be facilitated by simple and concise recommendations that would complement detailed guidelines and could be rapidly updated as important results from clinical trials become available.

\section{Acknowledgements}

Editorial support was provided by INNOTIO GmbH (Kreuzlingen, Switzerland) and funded by Novartis Pharma AG (Basel, Switzerland).

\section{References}

1 Miravitlles M, Soriano JB, García-Río F, et al. Prevalence of COPD in Spain: impact of undiagnosed COPD on quality of life and daily life activities. Thorax 2009; 64: 863-868.

2 European COPD Coalition. Prevalence in EU. www.copdcoalition.eu/?s=prevalence+EU\&op.x=0\&op.y=0 Date last accessed: December 17, 2015. Date last updated: 2015.

3 López-Campos JL, Ruiz-Ramos M, Soriano JB. Mortality trends in chronic obstructive pulmonary disease in Europe, 1994-2010: a joinpoint regression analysis. Lancet Respir Med 2014; 2: 54-62.

4 Feder G, Eccles M, Grol R, et al. Clinical guidelines: using clinical guidelines. BMJ 1999; 318: 728-730.

5 Schünemann HJ, Woodhead M, Anzueto A, et al. A guide to guidelines for professional societies and other developers of recommendations: introduction to integrating and coordinating efforts in COPD guideline development. An official ATS/ERS workshop report. Proc Am Thorac Soc 2012; 9: 215-218.

6 Broughton R, Rathbone B. What Makes a Good Clinical Guideline? www.medicine.ox.ac.uk/bandolier/painres/ download/whatis/whatareclinguide.pdf Date last accessed: December 17, 2015. Date last updated: May 2001.

7 Brusselle GG, Gaga M. ERS guidelines, statements and technical standards published in the ERJ in 2014: a year in review. Eur Respir J 2015; 45: 863-866.

8 Celli BR, Decramer M, Wedzicha JA, et al. An official American Thoracic Society/European Respiratory Society statement: research questions in COPD. Eur Respir J 2015; 45: 879-905.

9 Koblizek V, Chlumsky J, Zindr V, et al. Chronic obstructive pulmonary disease: official diagnosis and treatment guidelines of the Czech Pneumological and Phthisiological Society; a novel phenotypic approach to COPD with patient-oriented care. Biomed Pap Med Fac Univ Palacky Olomouc Czech Repub 2013; 157: 189-201.

10 National Institute for Health and Care Excellence. Chronic Obstructive Pulmonary Disease: Management of Chronic Obstructive Pulmonary Disease in Adults in Primary and Secondary Care (Partial Update). www.nice.org. uk/guidance/cg101 Date last accessed: December 17, 2015. Date last updated: 2010.

11 Harju T, Kankaanranta H, Katajisto $M$, et al. Keuhkoahtaumatauti. Käypä hoito-suositus päivitystiivistelmä. Duodecim 2014; 130: 1774-1776.

12 Kankaanranta H, Harju T, Kilpeläinen M, et al. Diagnosis and pharmacotherapy of stable chronic obstructive pulmonary disease: the Finnish guidelines. Basic Clin Pharmacol Toxicol 2015; 116: 291-307.

13 Societe de Pneumologie de Langue Francaise. Recommandation pour la pratique clinique: prise en charge de la BPCO. [Recommendation for the clinical practice management of COPD]. Rev Mal Respir 2010; 27: 522-548.

14 Vogelmeier C, Buhl R, Criée CP, et al. Leitlinie der Deutschen Atemwegsliga und der Deutschen Gesellschaft für Pneumologie und Beatmungsmedizin zur Diagnostik und Therapie von Patienten mit chronisch obstruktiver Bronchitis und Lungenemphysem (COPD). [Guidelines for the diagnosis and therapy of COPD issued by Deutsche Atemwegsliga and Deutsche Gesellschaft für Pneumologie und Beatmungsmedizin]. Pneumologie 2007; 61: e1-e40.

15 Bettoncelli G, Blasi F, Brusasco V, et al. The clinical and integrated management of COPD. An official document of AIMAR (Interdisciplinary Association for Research in Lung Disease), AIPO (Italian Association of Hospital Pulmonologists), SIMER (Italian Society of Respiratory Medicine), SIMG (Italian Society of General Medicine). Multidiscip Respir Med 2014; 9: 25.

16 Sliwiński P, Górecka D, Jassem E, et al. Polish respiratory society guidelines for chronic obstructive pulmonary disease. Pneumonol Alergol Pol 2014; 82: 227-263.

17 Health Ministry, Portugal. Diagnóstico e Tratamento da Doença Pulmonar Obstrutiva Crónica. [Diagnosis and Treatment of Chronic Obstructive Pulmonary Disease.] Standard No. 028/2011. www.dgs.pt/directrizes-da-dgs/ normas-e-circulares-normativas/norma-n-0282011-de-30092011-atualizada-a-10092013.aspx Date last accessed: February 5, 2015. Date last updated: September 10, 2013.

18 Chuchalin AG, Avdeev SN, Belevskiy AS, et al. Russian Respiratory Society Federal Guidelines on Diagnosis and Treatment of Chronic Obstructive Pulmonary Disease. http://pulmonology.ru/pulm/article/view/234/233 Date last accessed: December 17, 2015. Date last updated: 2014. 
Miravitlles M, Soler-Cataluña JJ, Calle M, et al. Spanish COPD guidelines (GesEPOC): pharmacological treatment of stable COPD. Spanish Society of Pulmonology and Thoracic Surgery. Arch Bronconeumol 2012; 48: $247-257$.

20 Miravitlles M, Soler-Cataluña JJ, Calle M, et al. Spanish guideline for COPD (GesEPOC). Update 2014. Arch Bronconeumol 2014; 50: Suppl. 1, 1-16.

21 Holm LE. National Guidelines for Care in Asthma and COPD - Support for Governance and Management Consultation Version. www.socialstyrelsen.se/sitecollectiondocuments/nr-astma-kol-vetenskapligt-underlag-2015. pdf Date last accessed: December 17, 2015. Date last updated: 2014.

22 Global Initiative for Chronic Obstructive Pulmonary Disease (GOLD). COPD: Global Strategy for Diagnosis, Management, and Prevention of COPD. www.goldcopd.org/guidelines-global-strategy-for-diagnosis-management. html Date last accessed: December 17, 2015. Date last updated: 2015.

23 Celli BR, Cote CG, Marin JM, et al. The body-mass index, airflow obstruction, dyspnea, and exercise capacity index in chronic obstructive pulmonary disease. N Engl J Med 2004; 350: 1005-1012.

24 Soler-Cataluña JJ, Martínez-García MA, Sánchez LS, et al. Severe exacerbations and BODE index: two independent risk factors for death in male COPD patients. Respir Med 2009; 103: 692-699.

25 Soler-Cataluña JJ, Alcázar-Navarrete B, Miravitlles M. The concept of control of COPD in clinical practice. Int J Chron Obstruct Pulmon Dis 2014; 9: 1397-1405.

26 Price D, West D, Brusselle G, et al. Management of COPD in the UK primary-care setting: an analysis of real-life prescribing patterns. Int J Chron Obstruct Pulmon Dis 2014; 9: 889-904.

27 Weiss G, Steinacher I, Lamprecht B, et al. Detection of chronic obstructive pulmonary disease in primary care in Salzburg, Austria: findings from the real world. Respiration 2014; 87: 136-143.

28 Bárbara C, Rodrigues F, Dias H, et al. Chronic obstructive pulmonary disease prevalence in Lisbon, Portugal: the burden of obstructive lung disease study. Rev Port Pneumol 2013; 19: 96-105.

29 Nacul L, Soljak M, Samarasundera E, et al. COPD in England: a comparison of expected, model-based prevalence and observed prevalence from general practice data. J Public Health 2011; 33: 108-116.

30 Lindberg A, Jonsson AC, Rönmark E, et al. Prevalence of chronic obstructive pulmonary disease according to BTS, ERS, GOLD and ATS criteria in relation to doctor's diagnosis, symptoms, age, gender, and smoking habits. Respiration 2005; 72: 471-479.

31 Roche N, Jebrak G, Caillaud D, et al. Real-life use of long-acting antimuscarinic agents following their approval for COPD treatment. Eur Respir J 2015; 45: 260-262.

32 Celli BR, Halbert RJ. Point: should we abandon FEV1/FVC $<0.70$ to detect airway obstruction? No. Chest 2010; 138: 1037-1040.

33 Sorino C, Battaglia S, Scichilone N, et al. Diagnosis of airway obstruction in the elderly: contribution of the SARA study. Int J Chron Obstruct Pulmon Dis 2012; 7: 389-395.

34 Mannino DM, Diaz-Guzman E. Interpreting lung function data using 80\% predicted and fixed thresholds identifies patients at increased risk of mortality. Chest 2012; 141: 73-80.

35 Miravitlles M, Calle M, Soler-Cataluña JJ. Clinical phenotypes of COPD: identification, definition and implications for guidelines. Arch Bronconeumol 2012; 48: 86-98.

36 Esteban C, Quintana JM, Moraza J, et al. BODE-index vs HADO-score in chronic obstructive pulmonary disease: which one to use in general practice? BMC Med 2010; 8: 28.

37 Puhan MA, Garcia-Aymerich J, Frey M, et al. Expansion of the prognostic assessment of patients with chronic obstructive pulmonary disease: the updated BODE index and the ADO index. Lancet 2009; 374: 704-711.

38 Vestbo J, Agusti A, Wouters EF, et al. Should we view chronic obstructive pulmonary disease differently after ECLIPSE? A clinical perspective from the study team. Am J Respir Crit Care Med 2014; 189: 1022-1030.

39 Celli BR. Predictors of mortality in COPD. Respir Med 2010; 104: 773-779.

40 Cote CG, Pinto-Plata VM, Marin JM, et al. The modified BODE index: validation with mortality in COPD. Eur Respir J 2008; 32: 1269-1274.

41 Marin JM, Carrizo SJ, Casanova C, et al. Prediction of risk of COPD exacerbations by the BODE index. Respir Med 2009; 103: 373-378.

42 Marin JM, Cote CG, Diaz O, et al. Prognostic assessment in COPD: health related quality of life and the BODE index. Respir Med 2011; 105: 916-921.

43 Ko FW, Tam W, Tung AH, et al. A longitudinal study of serial BODE indices in predicting mortality and readmissions for COPD. Respir Med 2011; 105: 266-273.

44 Hurst JR, Vestbo J, Anzueto A, et al. Susceptibility to exacerbation in chronic obstructive pulmonary disease. N Engl J Med 2010; 363: 1128-1138.

45 Hardin M, Cho M, McDonald ML, et al. The clinical and genetic features of COPD-asthma overlap syndrome. Eur Respir J 2014; 44: 341-350.

46 Menezes AM, Montes de Oca M, Pérez-Padilla R, et al. Increased risk of exacerbation and hospitalization in subjects with an overlap phenotype: COPD-asthma. Chest 2014; 145: 297-304.

47 Miravitlles M, Soriano JB, Ancochea J, et al. Characterisation of the overlap COPD-asthma phenotype. Focus on physical activity and health status. Respir Med 2013; 107: 1053-1060.

48 Barrecheguren M, Esquinas C, Miravitlles M. The asthma-chronic obstructive pulmonary disease overlap syndrome (ACOS): opportunities and challenges. Curr Opin Pulm Med 2015; 21: 74-79.

49 Benfante A, Sorino C, Scichilone N. The asthma-COPD overlap syndrome (ACOS): hype or reality? That is, a curiosity for the media or an opportunity for physicians? Shortness of Breath 2014; 3: 165-174.

50 Agustí A. Phenotypes and disease characterization in chronic obstructive pulmonary disease. Toward the extinction of phenotypes? Ann Am Thorac Soc 2013; 10: Suppl, S125-S130.

51 Finkelstein J, Cha E, Scharf SM. Chronic obstructive pulmonary disease as an independent risk factor for cardiovascular morbidity. Int J Chron Obstruct Pulmon Dis 2009; 4: 337-349.

52 Koshiol J, Rotunno M, Consonni D, et al. Chronic obstructive pulmonary disease and altered risk of lung cancer in a population-based case-control study. PLoS One 2009; 4: e7380.

53 Benfield T, Lange P, Vestbo J. COPD stage and risk of hospitalization for infectious disease. Chest 2008; 134: 46-53.

54 Sin DD, Man JP, Man SF. The risk of osteoporosis in Caucasian men and women with obstructive airways disease. Am J Med 2003; 114: 10-14. 
55 Rana JS, Mittleman MA, Sheikh J, et al. Chronic obstructive pulmonary disease, asthma, and risk of type 2 diabetes in women. Diabetes Care 2004; 27: 2478-2484.

56 Marquis K, Maltais F, Duguay V, et al. The metabolic syndrome in patients with chronic obstructive pulmonary disease. J Cardiopulm Rehabil 2005; 25: 226-234.

57 Miravitlles M, Molina J, Quintano JA, et al. Factors associated with depression and severe depression in patients with COPD. Respir Med 2014; 108: 1615-1625.

58 Fabbri LM, Boyd C, Boschetto P, et al. How to integrate multiple comorbidities in guideline development: article 10 in integrating and coordinating efforts in COPD guideline development. An official ATS/ERS workshop report. Proc Am Thorac Soc 2012; 9: 274-281.

59 Vincken W, Aumann J, Chen H, et al. Efficacy and safety of coadministration of once-daily indacaterol and glycopyrronium versus indacaterol alone in COPD patients: the GLOW6 study. Int J Chron Obstruct Pulmon Dis 2014; 9: 215-228.

60 ZuWallack R, Allen L, Hernandez G, et al. Efficacy and safety of combining olodaterol Respimat ${ }^{\circledR}$ and tiotropium HandiHaler $^{\circ}$ in patients with COPD: results of two randomized, double-blind, active-controlled studies. Int $J$ Chron Obstruct Pulmon Dis 2014; 9: 1133-1144.

61 Decramer M, Anzueto A, Kerwin E, et al. Efficacy and safety of umeclidinium plus vilanterol versus tiotropium, vilanterol, or umeclidinium monotherapies over 24 weeks in patients with chronic obstructive pulmonary disease: results from two multicentre, blinded, randomised controlled trials. Lancet Respir Med 2014; 2: 472-486.

62 Mahler DA, Decramer M, D’Urzo A, et al. Dual bronchodilation with QVA149 reduces patient-reported dyspnoea in COPD: the BLAZE study. Eur Respir J 2014; 43: 1599-1609.

63 Wedzicha JA, Decramer M, Ficker JH, et al. Analysis of chronic obstructive pulmonary disease exacerbations with the dual bronchodilator QVA149 compared with glycopyrronium and tiotropium (SPARK): a randomised, double-blind, parallel-group study. Lancet Respir Med 2013; 1: 199-209.

64 Kitaguchi Y, Komatsu Y, Fujimoto K, et al. Sputum eosinophilia can predict responsiveness to inhaled corticosteroid treatment in patients with overlap syndrome of COPD and asthma. Int J Chron Obstruct Pulmon Dis 2012; 7: 283-289.

65 Lim HS, Choi SM, Lee J, et al. Responsiveness to inhaled corticosteroid treatment in patients with asthma-chronic obstructive pulmonary disease overlap syndrome. Ann Allergy Asthma Immunol 2014; 113: 652-657.

66 Sobieraj DM, White CM, Coleman CI. Benefits and risks of adjunctive inhaled corticosteroids in chronic obstructive pulmonary disease: a meta-analysis. Clin Ther 2008; 30: 1416-1425.

67 Nannini LJ, Lasserson TJ, Poole P. Combined corticosteroid and long-acting beta ${ }_{2}$-agonist in one inhaler versus long-acting beta ${ }_{2}$-agonists for chronic obstructive pulmonary disease. Cochrane Database Syst Rev 2012; 9: CD006829.

68 Calverley PM, Stockley RA, Seemungal TA, et al. Reported pneumonia in patients with COPD: findings from the INSPIRE study. Chest 2011; 139: 505-512.

69 Crim C, Calverley PM, Anderson JA, et al. Pneumonia risk in COPD patients receiving inhaled corticosteroids alone or in combination: TORCH study results. Eur Respir J 2009; 34: 641-647.

70 Kew KM, Seniukovich A. Inhaled steroids and risk of pneumonia for chronic obstructive pulmonary disease. Cochrane Database Syst Rev 2014; 3: CD010115.

71 Siva R, Green RH, Brightling CE, et al. Eosinophilic airway inflammation and exacerbations of COPD: a randomised controlled trial. Eur Respir J 2007; 29: 906-913.

72 Pascoe S, Locantore N, Dransfield M, et al. Blood eosinophil counts, exacerbations, and response to the addition of inhaled fluticasone furoate to vilanterol in patients with chronic obstructive pulmonary disease: a secondary analysis of data from two parallel randomised controlled trials. Lancet Respir Med 2015; 3: 435-442.

73 Overington JD, Huang YC, Abramson MJ, et al. Implementing clinical guidelines for chronic obstructive pulmonary disease: barriers and solutions. J Thorac Dis 2014; 6: 1586-1596.

74 Corrado A, Rossi A. How far is real life from COPD therapy guidelines? An Italian observational study. Respir Med 2012; 106: 989-997.

75 Koblizek V, Pecen L, Zatloukal J, et al. Real-life GOLD 2011 implementation: the management of COPD lacks correct classification and adequate treatment. PLoS One 2014; 9: e111078.

76 Burgel P-R, Deslée G, Jebrak G, et al. Real-life use of inhaled corticosteroids in COPD patients versus the GOLD proposals: a paradigm shift in GOLD 2011? Eur Respir J 2014; 43: 1201-1203.

77 Roche N, Dalmay F, Perez T, et al. Impact of chronic airflow obstruction in a working population. Eur Respir J 2008; 31: 1227-1233.

78 Frith PA, Thompson PJ, Ratnavadivel R, et al. Glycopyrronium once-daily significantly improves lung function and health status when combined with salmeterol/fluticasone in patients with COPD: the GLISTEN study-a randomised controlled trial. Thorax 2015; 70: 519-527.

79 Welte T, Miravitlles M, Hernandez P, et al. Efficacy and tolerability of budesonide/formoterol added to tiotropium in patients with chronic obstructive pulmonary disease. Am J Respir Crit Care Med 2009; 180: 741-750.

80 Aaron SD, Vandemheen KL, Fergusson D, et al. Tiotropium in combination with placebo, salmeterol, or fluticasone-salmeterol for treatment of chronic obstructive pulmonary disease: a randomized trial. Ann Intern Med 2007; 146: 545-555.

81 Davis KJ, Landis SH, Oh Y-M, et al. Continuing to Confront COPD International Physician Survey: physician knowledge and application of COPD management guidelines in 12 countries. Int J Chron Obstruct Pulmon Dis 2014; 10: 39-55

82 Glaab T, Vogelmeier C, Hellmann A, et al. Guideline-based survey of outpatient COPD management by pulmonary specialists in Germany. Int J Chron Obstruct Pulmon Dis 2012; 7: 101-108.

83 Wong GWK, Miravitlles M, Chisholm A, et al. Respiratory guidelines - which real world? Ann Am Thorac Soc 2014; 11: Suppl. 2, S85-S91.

84 Alonso-Coello P, Rigau D, Sanabria AJ, et al. Quality and strength: the GRADE system for formulating recommendations in clinical practice guidelines. Arch Bronconeumol 2013; 49: 261-267.

85 Hilbink MA, Ouwens MM, Burgers JS, et al. A new impetus for guideline development and implementation: construction and evaluation of a toolbox. Implement Sci 2014; 9: 34. 